\title{
Design Methodology of an Online Greek Language Course
}

\author{
Panayiotis Zaphiris \\ Industrial and Manufacturing Eng. \\ Wayne State University \\ Detroit, MI 48202 \\ p.zaphiris@wayne.edu
}

\author{
Giorgos Zacharia \\ Media Laboratory \\ Massachusetts Institute of Technology \\ Cambridge, MA 02139 \\ lysi@media.mit.edu
}

\begin{abstract}
We present a participatory design methodology for developing an online community supported Modern Greek language course. The students of the classes collaborate in transcribing real audio lessons, publish and peer review shared notes. Participatory design was implemented as a four step process (a) Building bridges with the intended users (b) Map user needs and suggestions to the system (c) Develop a prototype (d) Integrate feedback and continue the iteration.
\end{abstract}

\section{Keywords}

Distance learning, online communities, participatory design.

\section{INTRODUCTION}

We describe the design methodology of Learn Greek Online (http://www.kypros.org/Greek). The course is currently composed of 105 real audio files (around 15 minutes each), online student notes, a collection of collaborative learning tools (message board, chat room) and an online dictionary and a spell checker.

\section{DESIGN METHODOLOGY}

\section{Participatory design}

Participatory design (PD) (often termed the "Scandinavian Challenge" [2]) refers to a design approach that focuses on the intended user of the service or product, and advocates the active involvement of users throughout the design process. User involvement is seen as critical both because users are the experts in the work practices supported by these technologies and because users ultimately will be the ones creating new practices in response to new technologies [3].

Blomberg and Henderson [3] characterize the PD approach as advocating three tenets:

- The goal is to improve the quality of life.

- The orientation is collaborative.

- The process is iterative.

\section{Design Approach}

Our focus has been to design an online learning community. We believed that this online interaction and community would increase our users' motivation, commitment and satisfaction with the online course. The Participatory Design methodology blends nicely with our goal. In particular, involving users during system development is thought to lead to greater user commitment, acceptance, usage, and satisfaction with the system [1].

In the design phase of the on-line Greek language course, we implemented PD as a four-step process [4].

\section{Building bridges with the intended users:}

This step opened lines of communication between intended users and the development team. Specifically this step involved the initialization of a multidisciplinary development team, identifying key groups of end users, and creating new methods of communication with users.

The development team came out of the Kypros-Net Inc. (http://www.kypros.org) group. Through their involvement in Cyprus and Greece related projects, they had longstanding relations with the intended user community.

The intended users have been especially people of the Greek Diaspora, travelers to Cyprus and Greece and other Greek speaking areas and people who are generally interested in the Greek culture and language or languages in general. In our case bridges with the intended users were build through our years of work at providing information about Cyprus through the web pages of Kypros-Net, Inc. who primarily attracts the same user population as our intended Greek language online course.

\section{Mapping user needs and suggestions to the system:}

Our conceptual design model has been "to design an online effective Greek language course that can build and sustain an online learning community of students".

Based on the questions and inquiries we received from our users we tried to match their needs (they wanted an easy to follow, both elementary and advanced course that they could attend at their own paste) with our conceptual design model.

\section{Developing a prototype}

The project consists of 105 audio files, which were originally recorded as Radio lessons in Modern Greek for English speakers back in 1960's. The lessons were retrieved from the archives of the Cyprus Broadcasting Corporation, 
digitized in Real Audio 5.0 format and published on-line. Although, an optional textbook accompanied the original Radio lessons, the lessons were designed as a complete standalone course. We used several tools to assist the students of the lessons, including an online English-GreekEnglish dictionary, a Greek spell checker and a web-based discussion board for the students of the lessons.

\section{Integrating feedback and continuing the iteration}

Feedback from our users and suggestions are continuously incorporated into our design through a series of additions and corrections. For example, we were asked to add an online notes section and to encode some files again because they were corrupted. An important element in the participatory design methodology is the direct involvement of the user in all stages of the design process. At some point, the users started exchanging through email written notes taken by the advanced users. This phenomenon suggested that we should provide the users with the capability to post their notes on the project's site. Two months later, the students of the Audio lessons have managed to transcribe 81 out of the 105 lessons, correct them through a peer review process among themselves and post them on the project's website. Six months after that, the students had transcribed and peer reviewed all 105 lessons. They have also compiled lists of verbs and vocabulary words used in the Audio Lessons, and other grammatical notes.

\section{DISCUSSION}

The students of the Audio courses included people with no knowledge of Greek language, bilingual members of the Greek Diaspora, as well as high-school professors of foreign languages. These students created an open online community whose collaboration has boosted the learning experience of the whole community. The web-based discussion board has proven to be the most constructive tool for the students learning experience and the main source of feedback for the maintainers of the project. The experiences shared on the discussion board include tricks and tips on how to record the audio files, installation of Greek fonts, learning methodologies and questions about the Greek language itself that arise from the lessons. They also used it to announce the availability of their personal notes.

The advanced users (some of them retired teachers of foreign languages) have taken a lead role in the vast majority of the threads on the discussion board, answering most of the questions and encouraging the beginners to study the lessons further. They have also become the communication interface between the maintainers of the project and the community's requests. The advanced users maintain the online notes pages and make sure to report to the authors any technical problems or questions coming from the other users.

As we can see from Figure 1, the accesses the audio lessons, the language tools, and the total access of the message board and the notes pages, all kept increasing exponentially. However, once we allowed our users to publish their own notes, there was a dramatic shift of traffic from the message board to the notes pages. The shift happened, probably because it was no longer necessary to visit the message board to find out where other users had posted their notes, since all were aggregated in a central location.

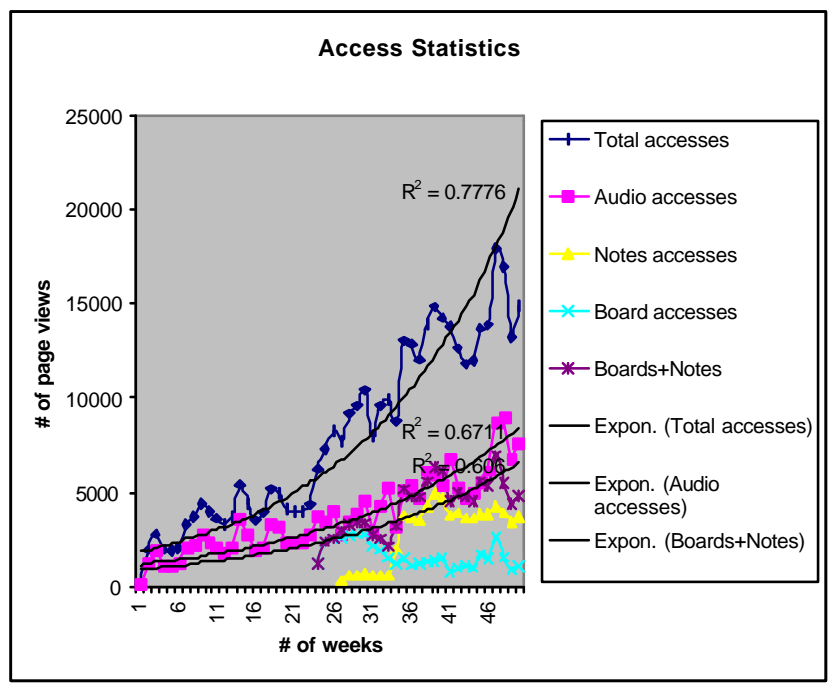

Figure 1 Access Statistics for Greek-Online site.

\section{CONCLUSIONS}

Design cannot be done independent of the social system in which it will be implemented. Software that will be embedded in a social process should be designed as part of that social process [5]. Participatory design implementation for the online Modern Greek language course has achieved our initial goal of developing an online community of students and has increased user's satisfaction and commitment.

\section{REFERENCES}

1. Baroudi, Olson \& Ives, "An Empirical Study of the Impact of User Involvement on System Usage and Information Satisfaction CACM, 29, 3 (March 1986), 232-238.

2. Bjerknes, Gro, Pelle Ehn and Morten Kyng, Eds. Computers and Democracy - A Scandinavian Challenge. Aldershot, England, 1987.

3. Blomberg, J.L. and Henderson, A., Reflections on Participatory Design: Lessons from the Trillium Experience, in Proceedings of CHI'90 (Seattle WA, April 1990), ACM Press, 353-359.

4. Ellis, R. D., Jankowski, T. B., \& Jasper, J. E. Participatory design of an Internet-based information system for aging services professionals. The Gerontologist, 38, 6 (1998), 743-748.

5. Preece, J. Online Communities: Designing Usability, Supporting Sociability John Wiley \& Sons, New York, NY, 2000 